\title{
MARKETING EM UNIDADES DE INFORMAÇÃO: ANÁLISE DOS ARTIGOS PUBLICADOS EM PERIÓDICOS DA CIÊNCIA DA INFORMAÇÃO E A RELAÇÃO COM A OFERTA DA DISCIPLINA DE MARKETINGNO CURSO DE GRADUAÇÃ̃O EM BIBLIOTECONOMIA
}

\author{
MARKETING IN INFORMATION UNITS: ANALYSIS OF ARTICLES PUBLISHED IN \\ INFORMATION SCIENCE JOURNALS AND ITS RELATIONSHIP WITH THE MARKETING \\ DISCIPLINE OFFER IN THE LABRARIANSHIP GRADUATION COURSE
}

\author{
Elenice Solovy \\ Graduada em Biblioteconomia \\ solovyelenice@gmail.com \\ Marli Dias de Souza Pinto \\ Doutora em Engenharia de Produção \\ PPGCiência da Informação - UFSC \\ marli.dias@ufsc.br
}

Recebido em: 26-12-2018

Aceito em:22-04-2019

\begin{abstract}
Resumo: As Unidades de Informação que desejam satisfazer as necessidades informacionais de seus usuários podem recorrer às estratégias e práticas de marketing. Este artigo tem como objetivo identificar as publicações em periódicos nacionais da Ciência da Informação sobre Marketing em Unidades de Informação e a relação de oferta da disciplina de Marketing nos cursos de Biblioteconomia brasileiros, no período entre 2012 e 2017. Quanto aos aspectos metodológicos, do ponto de vista dos procedimentos técnicos, é uma pesquisa bibliográfica e, do ponto de vista dos objetivos é uma pesquisa exploratória e descritiva, com abordagem quantitativa. Os resultados evidenciaram que as Revistas ACB, BIBLOS e RBBD obtiveram o maior número de publicações entre os anos de 2013 e 2014, tendo como destaque na produção de artigos a autora Ednéia Silva Santos Rocha e as instituições de onde provêm os autores são UNESP e USP. Em relação à disciplina de marketing, das 44 Universidades analisadas $23(53 \%)$ possuem marketing, 15 (34\%) possuem marketing como requisito obrigatório, oito (18\%) ofertam a disciplina como optativa. Evidencia que o Marketing como disciplina obrigatória e optativa, já é ofertada em mais de 50\% dos cursos de graduação em Biblioteconomia brasileiros A Região Sudeste apontou, maior número de publicações de artigo científico sobre o tema e, por conseguinte, tem o maior número de cursos que ofertam a disciplina de Marketing nos currículos dos cursos de graduação em Biblioteconomia. A região que mais oferta a disciplina de marketing em seus currículos tem maior número de publicação sobre o assunto.
\end{abstract}

Palavras-chave: Marketing. Marketing da Informação. Unidades de Informação. Marketing em organizações sem fins lucrativos.

\begin{abstract}
Information Units that provide the information they need to their customers can use marketing strategies and practices. This article has as specific theme the publications in periodicals of Information Science on Marketing in Information Units and the relation of the offer of the Marketing courses in Brazilian Librarianship, in the period from 2012 to 2017. As for the methodological aspects, from the point of view of the technical processes, is a bibliographical research and from the point of view of the objectives is an exploratory and descriptive research, with quantitative approach. The results showed that the ACB, BIBLOS and RBBD Magazines obtained the largest number of publications between the years of 2013 and 2014, highlighting the production of articles by Ednéia Silva Santos Rocha and the work institutions as authors are UNESP and USP. Regarding the marketing discipline, of the 44 universities (53\%) have marketing, 15 (34\%) have compulsory marketing, (18\%) offer the discipline as elective. Evidence of the Marketing As a compulsory and optional subject, it is already of greater importance in 50\% of the undergraduate courses in Librarianship, in the Southeastern Region, more articles published on the subject and, therefore, have the largest number of Programs that minister marketing disciplines in undergraduate curricula in librarianship. The region that offers the largest number of publications on the subject.
\end{abstract}

Keywords: Marketing. Information Marketing. Information Units. Marketing in nonprofit organizations. 


\section{INTRODUÇÃO}

A sociedade contemporânea encontra-se em processo de mudança e transformação, e consequentemente as organizações com ou sem fins lucrativos também. Para tanto, constantemente têm que reavaliar seus objetivos e estratégias para manter-se no mercado e, nesse contexto, aplicação do Marketing é um excelente aliado.

O marketing é uma disciplina de conhecimento da Ciência da Administração, mas mais recentemente está sendo empregada pela área da Ciência da Informação, de maneira mais específica, no curso de Biblioteconomia (AMARAL, 2007).

Nesse cenário encontram-se as Unidades de Informação, que se entende possuir características de organização sem fins lucrativos. De acordo com Kotler (1979), as organizações sem fins lucrativos não têm atividades fins de lucratividade, mas possuem papel importante na atração e retenção de recursos financeiros, materiais e humanos.

Ainda, na visão de Kotler (1979), estas organizações também enfrentam a concorrência e precisam ser geridas de forma eficaz e avaliando constantemente sua abordagem de prover serviços e produtos, para atender e entender a busca das necessidades informacionais de seus usuários.

A aplicação do marketing em Unidades de Informação, nacionalmente, foi objeto de estudo da autora Amélia Silveira em 1987, com o lançamento do livro Marketing em Bibliotecas e Serviços de Informação pela Editora do Instituto Brasileiro de Ciência e Tecnologia(IBICT).

Em 1993, no primeiro capítulo do livro sobre Marketing em Unidades de Informação: Estudos Brasileiros, Amélia Silveira e Sueli do Amaral, apresentaram uma revisão da literatura brasileira, compreendida no período de julho de 1977 a 1992 e, constataram que havia o interesse do tema pelo profissional da informação. Em contrapartida, apontaram a escassa publicação científica, referente à temática na área. (SILVEIRA, 1987; SILVEIRA,1993).

Em 1996,as autoras Amélia Silveira e Zélia Helena Moellmann Batistiotti publicaram um artigo apontando que, por recomendação da Associação Brasileira do Ensino de Biblioteconomia e Documentação (ABEBD), desde 1982, os currículos dos Cursos de Biblioteconomia no Brasil teriam que incluir marketing como disciplina, os resultados evidenciam que "todos os Cursos de graduação em Biblioteconomia da região sul oferecem marketing no currículo, seja como unidade ou subunidade em disciplina obrigatória ou como disciplina optativa".

Atualmente, merece destaque, a inserção em 2017, da disciplina CIN 7407 Marketing da Informação, como disciplina obrigatória nos cursos de graduação em Biblioteconomia, Arquivologia e Ciência da Informação, do Departamento de Ciência da Informação da Universidade Federal de Santa Catarina, (DPTCIn/UFSC) como aporte teórico-prático, para que os futuros profissionais busquem a excelência no desenvolvimento de serviços e produtos informacionais garantindo com isso a sobrevivência dessas Unidades.

Neste cenário e, com todas as evidências anteriormente apontadas, surgiu a motivação para elaborar o presente artigo que apresenta como objetivo geral: identificar as publicações em periódicos nacionais da 
Ciência da Informação sobre Marketing em Unidades de Informação e a relação do oferecimento da disciplina de Marketing nos cursos de Biblioteconomia brasileiros, no período de 2012/2017.

Especificamente, buscou-se a) Verificar a oferta da disciplina Marketing nos cursos de graduação em Biblioteconomia nacional; b) Pesquisar na Base de Dados em Ciência da Informação (BRAPCI) as publicações científicas no período estudado c) Analisar as publicações científicas recuperadas em relação: quantidade de artigos, pontuação Qualis CAPES, ano de publicação, autoria e Instituição e, d) Descrever a relação de artigos recuperados com a oferta da disciplina de Marketing obrigatório e optativa dos cursos de Biblioteconomia.

Quanto aos aspectos metodológicos em relação ao objetivo trata-se de um estudo exploratório e descritivo que se utilizou de dados secundários, para verificar sua aplicação em Unidades de Informação.

\section{MARKETING: ASPECTOS TEÓRICOS E CONCEITUAIS}

Derivado da língua inglesa, o termo marketing significa mercado em movimento, que teve suas técnicas usadas desde o início da civilização humana com o surgimento do comércio e, atualmente, popularizou-se. Porém, poucas pessoas conseguem conceituá-lo ou entendê-lo corretamente (AMARAL, 2007).

Tendo a troca como primeira forma de mercar, o marketing no início da civilização não era chamado desta forma. Os mercadores compravam e vendiam seus produtos visando desenvolver relacionamentos de longo prazo, o que atualmente se chamaria de equidade. Nos seus métodos de negócio, os mercadores até poderiam ser introspectivos, mas se eles não tivessem conhecimento de como satisfazer seus clientes enquanto faziam lucro, o comércio não teria sobrevivido (AMBLER, 2004).

O povo Fenício foi a civilização que mais sobressaiu na utilização das técnicas, devido as suas atividades serem baseadas no comércio. No entanto, foi nos Estados Unidos, na década de 40, que a prática do Marketing despontou, em razão da necessidade de esforço adicional para incrementar as vendas. Anteriormente, esse esforço era desnecessário, pois tudo o que era produzido, era vendido (SELEME et al., 2009).

A respeito do tema, Manzo (1982, p. 41) reforça:

O marketing teve sua origem na superprodução. Durante a $1^{\mathrm{a}}$. Guerra Mundial, a produção ficou concentrada no conflito, não havendo quase produção de bens de consumo. Ao terminar a guerra, as indústrias voltaram a produzir normalmente, não havendo, até então, dificuldade em colocar o produto no mercado, porque a procura era maior que a oferta. Esse sucesso provocou um imenso desenvolvimento industrial. Todos queriam produzir, e este fato, associado à crise econômica da época, gerou a depressão nos EUA. Foi nessa conjuntura que nasceu do marketing.

No Brasil, a utilização do marketing assim como o desenvolvimento do comércio é mais tardia se comparada a de alguns países. Iniciou-se com os vendedores ambulantes, chamados de mascates, que percorriam estradas e arruados, para vender seus produtos manufaturados (SELEME et al., 2009).

Visto pela maioria da população como um vilão - uma propaganda intrusa, utilizado para fazer a promoção e aumentar as vendas de produtos - o marketing, no entanto, é mais do que propaganda, é um 
trabalho de planejamento, implementação e controle das atividades de uma organização, buscando identificar necessidades e desejos dos usuários para melhor atendê-los (AMARAL, 2007).

$\mathrm{Na}$ literatura, há várias definições para o termo Marketing. A American Marketing Association (AMERICAN MARKETING ASSOCIATION, 2018), define o marketing como um conjunto de processos que vai desde a criação, a comunicação, a entrega e a troca de ofertas, agregando valor para os clientes, parceiros e para a sociedade.

Kotler e Fox (1994, p. 20), definem o marketing como:

[...] um processo social e gerencial pelo qual indivíduos e grupos obtêm o que necessitam e desejam através da criação, oferta e troca de produtos de valor com outros [...] O marketing é análise, o planejamento e implementação e o controle de programas cuidadosamente formulados e projetados para propiciar trocas voluntárias de valores com o mercado-alvo, com o propósito de atingir os objetivos organizacionais [...].

Com as mudanças na aplicação do marketing, onde o foco são os benefícios que a troca e relacionamento trazem para as organizações, Las Casas (2009, p.15) define o termo Marketing:

A área do conhecimento que engloba todas as atividades concernentes às relações de troca orientadas para a criação de valor dos consumidores, visando alcançar determinados objetivos de empresas ou indivíduos através de relacionamentos estáveis e considerando sempre o ambiente de atuação e impacto que essas relações causam no bem-estar da sociedade.

Por meio das definições apresentadas pela American Marketing Association (2018), e pelos autores Kotler (1994) e Las Casas (2009), pode-se afirmar que o marketing é o meio mais eficaz de promover serviços e satisfazer as necessidades dos seus reais e potenciais clientes. No caso das Unidades de Informação, as técnicas de marketing podem ser utilizadas para conhecer melhor seus usuários a fim de detectar suas necessidades informacionais, criar ou adaptar produtos e serviços para melhor atender suas expectativas.

\subsection{MARKETING EM INSTITUIÇÕES SEM FINS LUCRATIVOS}

O marketing teve suas raízes no setor lucrativo, tendo como objetivo principal a obtenção de lucros, em 1969 foi comprovado por Philip Kotler e Sidney Levy a sua aplicabilidade em organizações sem fins lucrativos (KOTLER, 1998). Segundo Cativelli (2013), o marketing pode ser aplicado tanto em empresas que visam lucros quanto em empresas que não têm essa finalidade. Para as organizações sem fins lucrativos, o marketing pode ser utilizado com o intuito de atingir as metas da instituição ou até mesmo incentivar o uso de serviços da organização.

Nessa perspectiva, Kotler (1998, p. 24), discorre sobre o tema da seguinte maneira:

A razão básica de uma organização que não visa lucro interessar-se pelos princípios formais do marketing, é que eles permitem que a organização se torne mais eficaz na obtenção de seus objetivos. As organizações em uma sociedade livre dependem das trocas voluntárias para que possam realizar seus objetivos. Os recursos devem ser atraídos, os empregados devem ser estimulados, os clientes devem ser encantados. O planejamento de incentivos 
apropriados é um passo importante no estímulo dessas trocas. O marketing é a ciência que mais se preocupa com o controle eficaz e eficiente das trocas.

Nesse sentido, pode-se afirmar que as ações de marketing direcionadas para produtos e serviços de informação em qualquer espaço e para qualquer utilidade pode:

[...] promover o acesso ao produto/serviço/informação, já que a sociedade precisa conhecêlos para despertar o interesse pelo seu acesso/uso. Partindo do princípio de que o marketing não está relacionado exclusivamente ao setor lucrativo, sendo possível aplicá-lo em unidades de informação. (ARAÚJO; SILVA; SILVA, 2011, p. 74).

No entanto, as organizações sem fins lucrativos, que inclui as Unidades de Informação, enfrentam a resistência da aplicação do marketing, por dois motivos: o primeiro é a visão distorcida que em geral as pessoas têm que o marketing é um instrumento de manipulação em prol de interesses individuais e o segundo aspecto é referente ao lucro em si, restringindo apenas quando há interesse financeiro envolvido, sem notar que o lucro não necessariamente se refere ao financeiro, mas a todo tipo de lucro que uma organização oferece e obtém de seu público (AMARAL, 2007).

Kotler (1998, p. 13), ressalta, que o público vê marketing como uso, muitas vezes, "abuso vigoroso, intruso da propaganda e da venda. Subentendendo que o marketing é responsável pela tentativa de "fazer que compradores indispostos comprem bens não desejados".

De acordo com Amaral (2007, p. 19), "Marketing não é, nem significa simplesmente vender, tampouco se limita apenas à divulgação ou a propaganda.”. A autora explica que as ações do marketing é o bom senso aplicado ao negócio iniciando sempre, com o cliente e não com produtos e serviços. Sua função é a identificação das necessidades, para a provisão de produtos e serviços, e que suas técnicas, também podem ser utilizadas pelas organizações que não visam lucro (AMARAL, 2007).

No Brasil, é visível o interesse dos profissionais da informação pelo assunto, mas na prática, a aplicação do marketing em Unidades de Informação não se realiza efetivamente. A não adoção das técnicas de marketing pelos gestores das Unidades de Informação, muitas vezes decorre pela falta de conhecimento dos mesmos referentes ao que se trata o marketing, tendo uma visão distorcida e acreditando que marketing é somente para promoção e venda de produtos (SANTOS, 2012).

Portanto, se as Unidades de Informação desejam satisfazer as necessidades de seus usuários, devem recorrer ao marketing. Desse modo, além de melhorar a sua imagem, conseguirão atrair novos usuários, atendendo melhor suas necessidades com a disponibilização de ofertas e serviços e trazendo desta forma maior satisfação.

\subsection{MARKETING COMO DISCIPLINA NOS CURSOS DE GRADUAÇÃO EM BIBLIOTECONOMIA NO BRASIL}

O Curso de Biblioteconomia no Brasil surgiu por volta do ano 1911, iniciando suas atividades em 1915 no Estado do Rio de Janeiro, na Biblioteca Nacional. Nesta época, o curso não possuía nenhum tipo de planejamento curricular, visando apenas atender às necessidades da Instituição. Nas décadas seguintes, 
começaram a surgir em outros estados novos cursos, exigindo maior comprometimento e estudos dos futuros profissionais (CASTRO, 2002).

A busca por uma base teórica sólida, referente às práticas biblioteconômicas, contribuiu para a consolidação de cursos e departamentos universitários e também para o surgimento de entidades que contribuíram para o fortalecimento da classe. Tais entidades, assim como os cursos de graduação na área, desempenharam e continuam desempenhando um papel de suma importância na consolidação da profissão do bibliotecário (CASTRO, 2002).

Segundo a Associação Brasileira de Educação em Ciência da Informação (ABECIN), no Brasil a área conta com 44 escolas que oferecem o curso de Biblioteconomia, na modalidade presencial e a distância (ASSOCIAÇÃO BRASILEIRA DE EDUCAÇÃO EM CIÊNCIA DA INFORMAÇÃO, 2018).

Por meio de levantamento de dados realizado nos sites das Instituições, foi possível traçar um panorama referente à oferta da disciplina de Marketing. Após examinar a grade curricular dos cursos de Biblioteconomia de cada Instituição, no site dos referidos cursos, aponta-se por região aquelas que apresentam a disciplina de Marketing como requisito obrigatório, optativo e as que não apresentam Marketing em sua grade curricular, este resultado consta no item 4.1 (Tabela 1).

\subsection{PERIÓDICOS CIENTÍFICOS DA CIÊNCIA DA INFORMAÇÃO}

Desde os primórdios, o conhecimento e a informação exerceram o papel fundamental para o desenvolvimento das civilizações. Nos dias atuais, a informação é a chave para uma sociedade democrática, na qual informação é poder. No entanto, devido diferenças sociais e econômicas cresce a disparidade entre os que possuem informação e aqueles que não têm acesso a ela (FUNDAÇÃO BIBLIOTECA NACIONAL, 2010).

Os meios de acesso e disseminação da informação são diversos, dentre eles, principalmente no âmbito científico, são os periódicos, que não só promovem o acesso, como é o principal meio de disseminação da ciência.

Originários das cartas e de atas utilizadas pelos cientistas para divulgar suas ideias e descobertas, os primeiros periódicos científicos surgiram na França e na Inglaterra, tendo o Philosophical Transactions da Royal Society como o primeiro voltado para a divulgação de resultados de pesquisas, impulsionando o surgimento de outros periódicos na Europa (MULLER, 2000).

No Brasil, os periódicos exercem um papel fundamental na difusão da informação e na comunicação no âmbito científico. Segundo Packer (2011), os periódicos científicos brasileiros são responsáveis por mais de um terço da publicação científica do Brasil desde 2009, permitindo que o Brasil alcançasse a $13^{a}$ posição no ranking internacional de produção científica que é medida pelo número de artigos publicados. A Scientific Electronic Library Online (SciELO), que publica e indexa os periódicos brasileiros online, atendeu em 2010 uma média mensal de 10,6 milhões de downloads de artigos.

Anualmente a Coordenação de Aperfeiçoamento de Pessoal de Nível Superior (Capes) realiza a 
avaliação dos periódicos nacionais de 49 áreas, com objetivo de classificar a produção científica dos programas de pós-graduação. Este processo é realizado por um comitê aprovado pelo Conselho Técnico-Científico da Educação Superior (CTC-ES) de cada área de avaliação, seguindo critérios disponibilizados nos Documentos de Área pela Capes (COORDENAÇÃO DE APERFEIÇOAMENTO DE PESSOAL DE NÍVEL SUPERIOR, 2018).

Conforme site da Capes, o Qualis "é o conjunto de procedimentos utilizados pela Capes para estratificação da qualidade da produção intelectual dos programas de pós-graduação" (COORDENAÇÃO DE APERFEIÇOAMENTO DE PESSOAL DE NÍVEL SUPERIO, 2018), e foi o critério da Classificação dos Periódicos Científicos da Ciência da Informação, utilizado no estudo para verificar as publicações sobre Marketing em Unidades de Informação, conforme apresentado no Quadro 3, na Análise dos Resultados desta pesquisa.

\section{PROCEDIMENTOS METODOLÓGICOS}

Quanto aos objetivos, esta pesquisa caracteriza-se como exploratória e descritiva. A pesquisa exploratória tem como objetivo proporcionar uma maior familiaridade com o problema da pesquisa, visando explicitar e construir hipóteses (GIL, 1991). Quanto à pesquisa descritiva, Gil (1991, p. 46), considera que ela possibilita "descrever as características de determinado fenômeno ou o estabelecimento de relações entre variáveis".

Em relação aos procedimentos técnicos adotados, trata-se de uma pesquisa bibliográfica realizada na primeira etapa sobre Marketing em Unidades de Informação, que para Oliveira (2010, p. 69) é "“[...] uma modalidade de estudo e análise de documentos de domínio científico tais como livros, enciclopédias, periódicos, ensaios críticos, dicionários, e artigos científicos”. Gil (2002) explica que o levantamento bibliográfico é uma etapa fundamental para termos ciência do que está disponível em bases de dados. A utilização deste método foi necessária para construir a fundamentação teórico-conceitual desta pesquisa através das teorias e conceitos.

Referente à análise dos dados, a pesquisa é também denominada quantitativa, descrita por Fonseca (2002) como um método capaz de quantificar os resultados da pesquisa e traduzir em números opiniões e informações para classificá-las e analisá-las, visando trabalhar com um nível de realidade para que a pesquisa atinja os objetivos de investigação.

Para a escolha das publicações periódicas analisadas no estudo, utilizou-se a Base de Dados Referencial de Artigos e Periódicos em Ciência da Informação (BRAPCI), na qual são indexados os conteúdos de um expressivo número de revistas científicas na área de Biblioteconomia e Ciência da Informação no Brasil.

$\mathrm{Na}$ BRAPCI, foram selecionados artigos que traziam em seu título, resumo ou palavras-chave, os termos pertinentes ao Marketing em Unidades de Informação, compreendido no período de 2012 a 2017, em todo o território nacional brasileiro. A pesquisa dos artigos foi realizada no período de junho a agosto de 2018. 
O termo de pesquisa "Unidades de Informação" foi escolhido por enquadrar qualquer tipo de unidade que coleta, trata, organiza e disponibiliza informações. No caso deste estudo, abrangendo arquivos, bibliotecas, centros de documentação e museus.

Foram excluídos deste estudo, artigos publicados em Anais e Eventos e em periódicos qualificados com Qualis C. A exclusão dos artigos com Qualis C deu-se por este estrato ser considerado NPC (não periódico científico). Segundo a Capes, os periódicos com esta classificação, não atendem os critérios mínimos correspondentes aos estratos de A1 a B5 e das boas práticas editoriais, conforme a Committee on Publication Ethics (COPE), além de não possuir a avaliação por pares, sendo considerado apenas um periódico de divulgação (COORDENAÇÃO DE APERFEIÇOAMENTO DE PESSOAL DE NÍVEL SUPERIOR, 2016).

\section{ANÁLISE DOS DADOS E INTERPRETAÇÃO DOS RESULTADOS}

Primeiramente, na análise dos dados da pesquisa, buscou-se cumprir o objetivo específico (a), que buscou verificar em todos os currículos do curso de Biblioteconomia nacionais disponíveis nas páginas dos cursos na Web, a situação da disciplina de Marketing em cada uma das Instituições de Ensino Superior, conforme apresentado na Tabela 1.

Tabela 1 - Cursos de Biblioteconomia no Brasil e a oferta da disciplina de Marketing

\begin{tabular}{l|c|c|c}
\hline \multicolumn{1}{c|}{ Região } & $\begin{array}{c}\text { Marketing Como } \\
\text { Disciplina Obrigatória }\end{array}$ & $\begin{array}{c}\text { Marketing Como Disciplina } \\
\text { Optativa }\end{array}$ & $\begin{array}{c}\text { Não Possui A Disciplina De } \\
\text { Marketing }\end{array}$ \\
\hline Norte & 1 & 1 & 1 \\
\hline Nordeste & 3 & 4 & 3 \\
\hline Centro-Oeste & 2 & - & 2 \\
\hline Sudeste & 5 & 3 & 7 \\
\hline Sul & 4 & - & 3 \\
\hline Total & $\mathbf{1 5}$ & $\mathbf{8}$ & $\mathbf{1 6}$ \\
\hline
\end{tabular}

Fonte: Dados da pesquisa (2018).

Conforme a Tabela 1, verificou-se que do total de 44 (100\%) cursos de Biblioteconomia brasileiros, presencial e a distância, 23 (53\%) possui marketing, 15 (35\%) marketing como requisito obrigatório e oito (18\%) como optativa. Sendo que 16 (36\%) não possuem a disciplina de marketing; quatro (9\%) sem indicação de funcionamento do curso e, um (2\%) não foi localizado no site a grade curricular.

Desse modo, visualiza-se que o Marketing como requisito obrigatório e optativo, já é ofertado em mais de $50 \%$ dos cursos de Biblioteconomia brasileiros, sobressaindo-se como maior oferta em disciplina obrigatória e optativa a Região Sudeste. 
$\mathrm{Na}$ continuidade, a pesquisa buscou atender o objetivo específico(b)que buscou pesquisar na Base de Dados em Ciência da Informação (BRAPCI) as publicações científicas no período estudado, conforme a Tabela 2.

Tabela 2- Marketing em periódicos científicos da Ciência da Informação

\begin{tabular}{|c|c|}
\hline Periódico & $\mathbf{N}^{0}$ Publicações e \% \\
\hline Revista Brasileira de Biblioteconomia e Documentação & $2(12 \%)$ \\
\hline BIBLOS & $2(12 \%)$ \\
\hline Revista ACB & $2(12 \%)$ \\
\hline Em Questão & $1(6 \%)$ \\
\hline Revista Analisando em Ciência da Informação & $1(6 \%)$ \\
\hline Informação Arquivística & $1(6 \%)$ \\
\hline Revista Brasileira de Biblioteconomia e Documentação & $1(6 \%)$ \\
\hline Perspectivas em Ciência da Informação & $1(6 \%)$ \\
\hline Revista Brasileira de Educação em Ciência da Informação & $1(6 \%)$ \\
\hline Liinc em revista & $1(6 \%)$ \\
\hline AtoZ: Novas Práticas em Informação e Conhecimento & $1(6 \%)$ \\
\hline Revista Digital de Biblioteconomia \& Ciência da Informação & $1(6 \%)$ \\
\hline Múltiplos Olhares em Ciência da Informação & $1(6 \%)$ \\
\hline Revista CRB8 Digital & $1(6 \%)$ \\
\hline Total & $\mathbf{1 7}(100 \%)$ \\
\hline
\end{tabular}

Fonte: Dados da pesquisa (2018).

Como apresentado na Tabela 2, o número de artigos recuperados na pesquisa realizada na base BRAPCI, no período de 2012 a 2017 foi de 17 artigos, sendo excluídos artigos publicados em Anais de Eventos e com Qualis C, permanecendo apenas publicações em periódicos qualificados pela Capes. Dos artigos recuperados com maior número de publicações foram os publicados nos periódicos: Revista ACB: Biblioteconomia em Santa Catarina, BIBLOS e Revista Brasileira de Biblioteconomia e Documentação (RBBD), com dois (12\%) artigos cada, os demais periódicos tiveram apenas uma publicação cada no período estudado, que somados todos totalizam $64 \%$.

O Quadro 1 refere-se ao objetivo (c) Analisar as publicações científicas recuperadas em relação a títulos dos artigos, pontuação Qualis CAPES, ano de publicação, autoria e Instituição. 
Quadro 1 - Publicações recuperadas em relação à artigos, pontuação Qualis, ano de publicação, título, autoria e Instituição

\begin{tabular}{|c|c|c|c|c|}
\hline Periódico & Qualis & Ano & Título & Autores/Instituição \\
\hline $\begin{array}{l}\text { Revista Brasileira } \\
\text { de } \\
\text { Biblioteconomia } \\
\text { e Documentação }\end{array}$ & B1 & 2017 & $\begin{array}{l}\text { A inteligência competitiva em } \\
\text { organizações especialistas } \\
\text { brasileiras: um breve estudo }\end{array}$ & $\begin{array}{l}\text { LAURINDO, Kariane Regina; } \\
\text { PEREIRA, Ana Maria; SPUDEIT, } \\
\text { Daniela Fernanda Assis de Oliveira - } \\
\text { Universidade do Estado de Santa } \\
\text { Catarina (UDESC). }\end{array}$ \\
\hline $\begin{array}{l}\text { Revista de } \\
\text { Ciência da } \\
\text { Informação e } \\
\text { Documentação }\end{array}$ & B1 & 2017 & $\begin{array}{l}\text { Estratégia de marketing digital para } \\
\text { unidades informacionais: estudo dos } \\
\text { websites de arquivos e bibliotecas } \\
\text { públicas estaduais. }\end{array}$ & $\begin{array}{l}\text { GIROTO, Luan; FORMENTINI, } \\
\text { Rosangela - Universidade Estadual } \\
\text { Paulista Júlio de Mesquita Filho } \\
\text { (UNESP). }\end{array}$ \\
\hline Em Questão & A2 & 2017 & $\begin{array}{l}\text { Indicadores de marketing digital } \\
\text { para websites de arquivos públicos } \\
\text { estaduais }\end{array}$ & $\begin{array}{l}\text { FERREIRA, Luan Henrique Giroto; } \\
\text { CALDAS, Rosângela Formentini - } \\
\text { Universidade Estadual Paulista Júlio de } \\
\text { Mesquita Filho (UNESP). }\end{array}$ \\
\hline $\begin{array}{l}\text { Revista } \\
\text { Analisando em } \\
\text { Ciência da } \\
\text { Informação }\end{array}$ & B5 & 2016 & $\begin{array}{l}\text { Gestão de marketing em unidades } \\
\text { de informação: estudo de caso do } \\
\text { centro de documentação e arquivo } \\
\text { da câmara de vereadores de } \\
\text { Piracicaba (SP) }\end{array}$ & $\begin{array}{l}\text { RAGANÇA, Fábio FerreiraCoelho; } \\
\text { ZACCARIA, Rosana Borges - } \\
\text { Universidade Metodista de Piracicaba } \\
\text { (UNIMEP). }\end{array}$ \\
\hline $\begin{array}{l}\text { Informação } \\
\text { Arquivística }\end{array}$ & B5 & 2015 & $\begin{array}{l}\text { Difusão em arquivos: uma função } \\
\text { arquivística, informacional e } \\
\text { comunicacional. }\end{array}$ & $\begin{array}{l}\text { ROCKEMBACH, Moisés - } \\
\text { Universidade Federal do Rio Grande } \\
\text { do Sul (UFRGS). }\end{array}$ \\
\hline $\begin{array}{l}\text { Revista Brasileira } \\
\text { de } \\
\text { Biblioteconomia } \\
\text { e Documentação }\end{array}$ & B1 & 2015 & $\begin{array}{l}\text { Promoção da informação na web: } \\
\text { pesquisa aplicada à gestão do } \\
\text { Facebook de olho na CI }\end{array}$ & $\begin{array}{l}\text { FREIRE, Isa Maria; COSTA, Cristiano } \\
\text { Santana da - Universidade Federal da } \\
\text { Paraíba (UFPB). }\end{array}$ \\
\hline $\begin{array}{l}\text { Perspectivas em } \\
\text { Ciência da } \\
\text { Informação }\end{array}$ & A1 & 2014 & $\begin{array}{l}\text { Atributos determinantes da baixa } \\
\text { utilização de bibliotecas: estudo em } \\
\text { uma instituição de ensino pública } \\
\text { federal }\end{array}$ & $\begin{array}{l}\text { DANASCENO, Andreia Cristina.; } \\
\text { MESQUITA, José Marcos Carvalho } \\
\text { de. - Universidade FUMEC (FUMEC). }\end{array}$ \\
\hline $\begin{array}{l}\text { Revista Brasileira } \\
\text { de Educação em } \\
\text { Ciência da } \\
\text { Informação }\end{array}$ & B5 & 2014 & $\begin{array}{l}\text { Marketing e comunicação nos } \\
\text { serviços de curadoria de } \\
\text { informação: eixos teóricos e } \\
\text { reflexões desenvolvidas em } \\
\text { contexto acadêmico }\end{array}$ & $\begin{array}{l}\text { ERNESTO, Eliseu.; SANTOS, } \\
\text { Henriqueta; CAVALINHOS, Marcia.; } \\
\text { VITORINO, Maria Jose; GERALDES, } \\
\text { Ricardo M.; GRACEL, Paulo; } \\
\text { MATOS, Silvia Lazary de; } \\
\text { LAUREANO, Fernando; PATRICIO, } \\
\text { Sonia; ESTRELA, Osvaldo. - } \\
\text { Universidade Nova de Lisboa - Angola } \\
\text { (NOVA). }\end{array}$ \\
\hline BIBLOS & B3 & 2014 & $\begin{array}{l}\text { O papel da qualidade e do } \\
\text { marketing no serviço de referência }\end{array}$ & $\begin{array}{l}\text { COSSICH, Marília- Universidade } \\
\text { Federal do Rio de Janeiro (UFRJ). }\end{array}$ \\
\hline Liinc em Revista & B1 & 2014 & $\begin{array}{l}\text { Propriedade intelectual, } \\
\text { comunidades tradicionais e }\end{array}$ & $\begin{array}{l}\text { MELLO, Janaina Cardoso de - } \\
\text { Universidade Federal de Sergipe } \\
\text { (UFS). }\end{array}$ \\
\hline
\end{tabular}




\begin{tabular}{|c|c|c|c|c|}
\hline & & & $\begin{array}{l}\text { patrimônio imaterial em museus de } \\
\text { ciência e tecnologia. }\end{array}$ & \\
\hline Revista ACB & B2 & 2013 & $\begin{array}{l}\text { A atuação do marketing nas } \\
\text { unidades de informação }\end{array}$ & $\begin{array}{l}\text { ROCHA, Ednéia Silva Santos; MAIA, } \\
\text { Margareth Barros-Universidade de São } \\
\text { Paulo (USP). }\end{array}$ \\
\hline $\begin{array}{l}\text { AtoZ: Novas } \\
\text { Práticas em } \\
\text { Informação e } \\
\text { Conhecimento }\end{array}$ & B2 & 2013 & $\begin{array}{l}\text { El "lavado verde" em } \\
\text { lacomunicación gráfica de } \\
\text { lapublicidad de condomínios } \\
\text { residencialesen Caruaru- } \\
\text { Pernambuco }\end{array}$ & $\begin{array}{l}\text { SILVA, Tamires Maria de Lima; } \\
\text { OLIVEIRA, Emilio Augusto Gomes de } \\
\text { - Universidade Federal de Pernambuco } \\
\text { (UFPE). }\end{array}$ \\
\hline $\begin{array}{l}\text { Revista Digital de } \\
\text { Biblioteconomia } \\
\text { \& Ciência da } \\
\text { Informação }\end{array}$ & B1 & 2013 & $\begin{array}{l}\text { Marketing aplicado em bibliotecas: } \\
\text { análise de conteúdo dos artigos } \\
\text { publicados em periódicos da ciência } \\
\text { da informação }\end{array}$ & $\begin{array}{l}\text { CATIVELLI, Adriana Stefani - } \\
\text { Universidade Federal de Santa } \\
\text { Catarina(UFSC). }\end{array}$ \\
\hline $\begin{array}{l}\text { Múltiplos } \\
\text { Olhares em } \\
\text { Ciência da } \\
\text { Informação }\end{array}$ & B5 & 2013 & $\begin{array}{l}\text { Unidades de informação no século } \\
\text { XXI: um enfoque das funções } \\
\text { desempenhadas por web sites de } \\
\text { bibliotecas }\end{array}$ & $\begin{array}{l}\text { PAIVA, Rodrigo Oliveira de- } \\
\text { Universidade Federal do Pará (UFPA). }\end{array}$ \\
\hline Revista ACB & B2 & 2012 & $\begin{array}{l}\text { Estratégia de marketing em } \\
\text { unidades de informação: o uso de } \\
\text { ferramentas da web } 2.0\end{array}$ & $\begin{array}{l}\text { ROCHA, Ednéia Silva Santos; MAIA, } \\
\text { Margareth Barros- Universidade de São } \\
\text { Paulo (USP). }\end{array}$ \\
\hline BIBLOS & B3 & 2012 & $\begin{array}{l}\text { Divulgação da biblioteca da divisão } \\
\text { de gestão do conhecimento da } \\
\text { secretaria municipal de educação e } \\
\text { cultura da cidade do Rio Grande/RS }\end{array}$ & $\begin{array}{l}\text { CORRÊA, Tatiane PriscilaPinto; } \\
\text { SILVA, Vanessa Brum da- } \\
\text { Universidade Federal do Rio Grande } \\
\text { (FURG). }\end{array}$ \\
\hline $\begin{array}{l}\text { Revista CRB-8 } \\
\text { Digital }\end{array}$ & B5 & 2012 & $\begin{array}{l}\text { A aplicação de conceitos e práticas } \\
\text { de marketing: um estudo de caso do } \\
\text { sistema de bibliotecas dos Centros } \\
\text { Educacionais Unificados - C.E.U.s }\end{array}$ & $\begin{array}{l}\text { MATOS, Denílson Santos de; } \\
\text { OLIVEIRA, Emerson Soares de; } \\
\text { AGUIAR, Francisco Lopes de- } \\
\text { Faculdades Integradas Coração de } \\
\text { Jesus (FAINC). }\end{array}$ \\
\hline
\end{tabular}

Fonte: Dados da pesquisa (2018).

Conforme o Quadro 1, 17 (100\%) dos artigos com classificação Qualis Capes, apresentou-se da seguinte maneira: Qualis B1(29\%), B5 (29\%), B2 (18\%), B3 (12\%), A1 (6\%) e A2 (6\%). Verificou-se que a maioria dos artigos pesquisados tem classificação Capes B1 e B5, com cinco periódicos cada, em segundo lugar classificação B2 com três periódicos, em terceiro B3 com dois periódicos e por fim a classificação A1e A2, com um periódico cada.

$\mathrm{Na}$ análise do quantitativo de artigos por ano, a maior produção de artigos sobre a temática ocorreu em 2013 (23\%) e 2014 (23\%), depois em 2012 e 2017, com 18\% cada ano; e, por fim, 2015 (12\%) e 2016 (6 \%), com menor percentual de publicação.

Com relação à autoria dos artigos, foi identificado um total de 37 autores e coautores, sendo 17 autores e 20 coautores os que produziram os 17 artigos. A autora que obteve destaque na produção foi Ednéia Silva 
Santos em coautoria com Margareth Barros Maia, com dois artigos, os demais autores e coautores, escreveram somente um (1) artigo cada. O resultado engloba todos os tipos de autoria e evidencia o número de vezes em que cada autor aparece por artigo.

Os 17 artigos, foram publicados por 17 autores com 20 coautorias provenientes de 15 instituições de ensino, apresentadas a seguir por região. A região Sudeste apresentou o total de 6 (40\%), Região Sul 4 (27\%), Nordeste $3(20 \%)$ e Norte $1(6 \%)$ e 1(6\%) publicação internacional, da Universidade Nova de Lisboa, em Angola.

Os autores e coautores de acordo com as instituições informadas que mais publicaram, estão na Universidade Estadual Paulista "Júlio de Mesquita Filho" (UNESP), Universidade de São Paulo (USP), com duas publicações cada, as demais publicaram apenas um artigo.

E, por fim, visando cumprir o objetivo: d) Descrever a relação de artigos recuperados com a oferta do curso de Biblioteconomia, como requisito obrigatório e optativo da oferta da disciplina de Marketing no curso de Biblioteconomia, a Região Sudeste apresentou o maior percentual, sendo cinco disciplinas de marketing obrigatórias e três optativas, validando a relação de artigos publicados com a oferta da disciplina de Marketing em Unidades de Informação.

\section{CONSIDERAÇÕES FINAIS}

Por meio deste estudo, pôde-se inferir que o marketing é uma ferramenta de apoio para o profissional da informação, suas técnicas quando bem utilizadas ajudam na promoção dos serviços oferecidos, proporcionando melhores resultados na transferência da informação e maior satisfação dos usuários, reforçando a importância do conhecimento do marketing em organizações sem fins lucrativos.

O objetivo principal deste artigo foi identificar as publicações em periódicos nacionais da Ciência da Informação sobre Marketing em Unidades de Informação e a relação do oferecimento da disciplina de Marketing nos cursos de Biblioteconomia brasileiros. Na busca realizada na base BRAPCI foram recuperados 17 artigos no período entre 2012 e 2017 e percebeu-se que o resultado não apresenta uma quantidade expressiva de publicações sobre Marketing em Unidades de Informação, o que reforça a necessidade de maior incentivo em pesquisas sobre o assunto, uma vez que entende-se que os profissionais da informação podem utilizar as estratégias, técnicas e práticas do marketing para agregar valor aos serviços e produtos e, satisfazer necessidades informacionais de seus usuários.

$\mathrm{Na}$ análise das publicações científicas, constatou-se que dois artigos foram publicados em periódicos com maior classificação Capes A1 e A2, tendo a autora Ednéia Silva Santos e a coautora Margareth Barros Maia com maior número de publicações no período estudado.

Os autores das instituições com maior destaque na produção de artigos foram Universidade Estadual Paulista Júlio de Mesquita Filho (UNESP) e Universidade de São Paulo (USP).

A Região Sudeste foi a que apresentou as universidades que possuem o Marketing como requisito obrigatório e optativo, ofertado em mais dos $50 \%$ dos cursos de Biblioteconomia brasileiros, e consequente 
possui maior oferta em disciplina obrigatória e optativa e, por conseguinte, como maior número de artigos publicados sobre o tema.

Por fim, espera-se que este estudo sirva como incentivo para futuras pesquisas na área e, que venha a contribuir para o avanço das estratégias, bem como na inovação na gestão necessária às Unidades de Informação na utilização de recursos tecnológicos diversos.

\section{REFERÊNCIAS}

AMERICAN MARKETING ASSOCIATION. Releases new definition for marketing 2008.Chicago: 14 jan. 2008. Disponível em:

https://archive.ama.org/archive/AboutAMA/Documents/American\%20Marketing\%20Association\%20Releas es\%20New\%20Definition\%20for\%20Marketing.pdf. Acesso em: 21 fev. 2018.

AMARAL, S. A. do. Marketing na ciência da informação. Brasília: Editora Universidade de Brasília, 2007.ISBN 9788523009526.

AMBLER, T. A nova lógica dominante Marketing: vistas do elefante. London: Centre for Marketing of London Business School, 2004.

ARAÚJO, W. S.; SILVA, M. B.; SILVA, A. K. A.O uso do marketing na comunicação de produtos e serviços em unidades de informação: o caso da seção de multimeios da biblioteca central da UFPB.

Biblionline, João Pessoa, v. 2, n. 7, p.73-88, 2011.ISSN 1809-4775. Disponível em:

http://periodicos.ufpb.br/ojs2/index.php/biblio/article/view/9760/6931. Acesso em: 01 set. 2018.

ASSOCIAÇÃO BRASILEIRA DE EDUCAÇÃO EM CIÊNCIA DA INFORMAÇÃO - ABECIN. Cursos. Disponível em: http://www.abecin.org.br/cursos/. Acesso em: 26 abr. 2018.

BASE DE DADOS REFERENCIAIS DE ARTIGOS DE PERIÓDICOS EM CIÊNCIA DA

INFORMAÇÃO (BRAPCI). 2011. Disponível em: http://old.brapci.inf.br. Acesso em: 05 abr. 2018.

CASTRO, C. A. (Org.). Ciência da Informação e Biblioteconomia: múltiplos discursos. São Luís: EDUMA; EDFAMA, 2002.ISBN 85·7041-473-0.

CATIVELLI, A. S. Marketing aplicado em bibliotecas: análise de conteúdo dos artigos publicados em periódicos da ciência da informação. Revista Digital de Biblioteconomia \& Ciência da Informação, v. 11, n. 3, 2013.ISSN 1678-765X. Disponível em:

http://www.sbu.unicamp.br/seer/ojs/index.php/rbci/article/view/3876/pdf_43. Acesso em: 01 jan. 2018.

COORDENAÇÃO DE APERFEIÇOAMENTO DE PESSOAL DE NÍVEL SUPERIOR. Considerações sobre Qualis Periódicos: Interdisciplinar. Brasília, 2016. 3 p. Disponível em:

http://www.capes.gov.br/images/documentos/Qualis_periodicos_2016/Consideracoes_Qualis_Periodicos_Ar ea_inter.pdf. Acesso em: 15 abr. 2018.

COORDENAÇÃO DE APERFEIÇOAMENTO DE PESSOAL DE NÍVEL SUPERIOR. Qualis-Periódicos. Disponível em:

https://sucupira.capes.gov.br/sucupira/public/index.jsf;jsessionid=5khRVNS5JRYApmsu7YDp7KzG.sucupi ra-208. Acesso em: 07 jul. 2018.

FONSECA, J. J. S. da. Metodologia da pesquisa científica. Ceará: Universidade Estadual do Ceará, 2002.Apostila. 
FUNDAÇÃO BIBLIOTECA NACIONAL. Biblioteca Pública: princípios e diretrizes. Rio de Janeiro: Fundação Biblioteca Nacional, 2010. 160 p.

GIL, A. C. Como elaborar projetos de pesquisa. 4. ed. São Paulo: Atlas, 2002.ISBN 85-224-3169-8.

GIL, A. C. Como elaborar projetos de pesquisa. 3. ed. São Paulo: Atlas, 1991.ISBN 85-224-3169-8.

KOTLER, P.; FOX, K. F.A. Marketing estratégico para instituições educacionais. Tradução Ailton Bonfim Brandão. São Paulo: Atlas, 1994.

KOTHER, P. Administração de marketing: análise, planejamento, implementação e controle.5. ed. São Paulo: Atlas, 1998.ISBN 85-224-1825-X.

KOTLER, P. Marketing para organizações que não visam o lucro. São Paulo: Atlas, 1979.ISBN-13 9788522403974.

LAS CASAS, A. L. Marketing: conceitos, exercícios e casos. 8. ed. São Paulo: Atlas. 2009.ISBN 9788522453979.

MANZO, J. M. Fundamentos de marketing. 4. ed. Rio de Janeiro: Zahar, 1982.

MUELLER, S. P. M. O periódico científico.In: CAMPELLO, B. S.; CENDÓN, B. V.; KREMER, J. M. (Org.). Fontes de informação para pesquisadores e profissionais. Belo horizonte: Editora da UFMG, 2000. p.73-95. ISBN 85-7041-209-6.

OLIVEIRA, M. M. de. Como fazer pesquisa qualitativa. 3. ed. Petrópolis, RJ: Vozes, 2010.ISBN 9788532633774 .

PACKER, A. L. Os periódicos brasileiros e a comunicação da pesquisa nacional. Rev. USP[online], n.89, p. 26-61, 2011. ISSN 0103-9989.

SANTOS, J. F. dos. Marketing na gestão de bibliotecas públicas. 2012. 197 f. Dissertação (Mestrado em Ciência da Informação) - Universidade Federal da Bahia, Salvador, 2012. Disponível em: https://repositorio.ufba.br/ri/handle/ri/7824. Acesso em: 23 set. 2018.

SELEME, A. et al. O desenvolvimento do Marketing: uma perspectiva histórica. REGE: Revista de Gestão USP, São Paulo, v. 1, n. 16, p.89-102, 2009, Disponível em: http://www.regeusp.com.br/arquivos/767.pdf. Acesso em: 12 fev. 2018.

SILVEIRA, A. A literatura brasileira de marketing em bibliotecas e serviços de informação: de julho de 1977 a julho de 1992. In: SILVEIRA, A. AMARAL, S. A do (Comp.). Marketing em unidades de informação: estudos brasileiros. Brasília: IBICT/SENAI, 1993. p.23-73. 